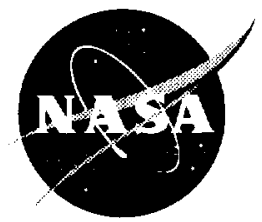

\title{
Performance of the MIR Cooperative Solar Array After 2.5 Years in Orbit
}

Thomas W. Kerslake and David J. Hoffman

Glenn Research Center, Cleveland, Ohio

Prepared for the

34th Intersociety Energy Conversion Engineering Conference sponsored by the Society of Automotive Engineers

Vancouver, British Columbia, Canada, August 1-5, 1999

National Aeronautics and

Space Administration

Glenn Research Center 


\section{Acknowledgments}

The authors wish to acknowledge the crews of the Mir space station for reconfiguring the station to permit data collection and Rocket Space Corporation Energia (Korolev, Russia) for providing the data to NASA under contract NAS15-10110.

Available from

NASA Center for Aerospace Information 7121 Standard Drive Hanover, MD 21076

Price Code: A03
National Technical Information Service 5285 Port Royal Road Springfield, VA 22100 Price Code: A03 


\title{
Performance of the Mir Cooperative Solar Array After 2.5 Years in Orbit
}

\author{
Thomas W. Kerslake and David J. Hoffman \\ National Aeronautics and Space Administration \\ Glenn Research Center \\ Cleveland, Ohio 44135
}

\begin{abstract}
The Mir Cooperative Solar Array (MCSA) was developed jointly by the United States and Russia to produce $6 \mathrm{~kW}$ of power for the Russian space station Mir. Four, multiorbit test sequences were executed between June 1996 and December 1998 to measure MCSA electrical performance. A dedicated Fortran computer code was developed to analyze the detailed thermal-electrical performance of the MCSA. The computational performance results compared very favorably with the measured flight data in most cases. Minor performance degradation was detected in one current generating section of the MCSA. Yet overall, the flight data indicated the MCSA was meeting and exceeding performance expectations. There was no precipitous performance loss due to contamination or other causes after 2.5 years of operation. In this paper, we review the MCSA flight electrical performance tests, data and computational modeling and discuss findings from data comparisons with the computational results.
\end{abstract}

\section{INTRODUCTION}

The objective of the Mir Cooperative Array (MCSA) project was to increase the electrical power available to the 10-year old Russian space station Mir [1]. The added power extended Mir's useful life and supported U.S. experiments conducted under the Phase 1 International Space Station (ISS) Program. This objective was met by replacing an existing, degraded photovoltaic array with a new array developed cooperatively by the U.S. and Russia. The MCSA was launched to Mir by the space shuttle Atlantis during the November 1995 STS-74 mission and installed on the Kvant-1 module in May 1996.

A second program objective was to reduce technical risk for the ISS Phase II Program. Since MCSA and ISS solar array panel technology is nearly the same, MCSA operation offered an opportunity to gather multi-year performance data on the ISS solar array technology prior to its implementation on ISS. Also, by correlating the test data with computational predictions, ISS Electrical Power System (EPS) performance codes [2] could be further validated. These codes provide invaluable information to resource managers that plan electric power utilization for ISS mission operations.

Thus far, orbital performance data have been gathered during tests in June 1996, December 1996, November 1997 and December 1998. An earlier paper [3] documented results from the first two tests. In this paper, data and computational results are compared for all four tests covering the time period from array beginning-of-life to 2.5 years of operation.

\section{DESCRIPTION OF MCSA HARDWARE AND INSTALLATION}

The MCSA consists of 84 Photovoltaic Panel Modules (PPMs) [4] mounted in pairs on 42 Russian Module Frame Assemblies or panels. Each PPM has 80 seriesconnected, $8 \times 8 \mathrm{~cm}$, silicon photovoltaic cells with $15 \%$ average efficiency. The cells are mounted on a flexible polyimide/glass scrim cloth substrate and connected via a copper flat printed circuit (FPC). PPMs are connected to form 12 current generators (GSs), each with either 6 or 8 PPMs in parallel. Generators are numbered GS1, GS2, etc. outward from the MCSA base toward the tip. Long power cables connect MCSA generators to current regulators located in the Mir Core module. Current regulator output voltage is maintained at $28.5 \pm 0.5 \mathrm{VDC}$. Figure 1 shows a photograph of the MCSA (foreground) installed on the Mir Kvant-1 module. The MCSA has a deployed length of $18 \mathrm{~m}$, a width of $2.7 \mathrm{~m}$, a mass (including deployment mechanism) of $479 \mathrm{~kg}$ and a beginning-of-life power of approximately $6 \mathrm{~kW}$. More details can be found in [3].

\section{MIR FLIGHT ATTITUDE AND ORBIT MECHANICS}

Four test periods were selected to measure MCSA performance over three successive orbits. Table 1 summarizes the Mir flight attitude and orbit information pertinent to these tests. Mir flew solar inertial in a nearcircular, $51.6^{\circ}$ inclination orbit. Flight attitudes and orbit conditions were chosen to provide the MCSA with optimum solar illumination, i.e. near normal solar incidence and no shadowing. To track the Sun, the MCSA solar array drive was automatically commanded to move to one of the 16 discrete angular zones with $\pm 3^{\circ}$ 
uncertainty. The resulting solar tracking error is reported in Table 1.

\section{INSTRUMENTATION AND TEST PROCEDURES}

MCSA generator currents were measured by current regulators using magnetic amplifiers with $5 \%$ accuracy on a 60-amp full scale. This resulted in a current measurement uncertainty of \pm 1.5 amps. PPM temperatures on the generators 1,2 and 3 were measured using platinum resistance temperature devices. Resistance values were measured using a Wheatstone bridge circuit with $\pm 1 \%$ accuracy. This resulted in a temperature measurement uncertainty of $\pm 3.5^{\circ} \mathrm{C}$. PPM temperature data were only obtained in June 1996, prior to instrumentation failures.

Prior to the test orbits, the Mir flight attitude was established to provide optimum solar illumination for the MCSA. The MCSA is paralleled to the same current regulators that are used by the companion array on Kvant-1 and part of a Mir core module array. Thus, over the 3-orbit test sequence, the Mir cosmonaut crew disconnected and sequentially reconnected the power supply feeds from the various arrays during the orbital eclipse periods. In the June 1996 test, MCSA currents were derived by differencing the regulator current data of sequential orbits. The error introduced from this approach was primarily due to orbit-to-orbit variation in environmental heating. Based on current measurements from several independently connected core array generators, this error was estimated to be $\pm 2 \%$. For the last three tests, however, single orbit measurements were obtained for MCSA generators only. No data were obtained from MCSA GS11 and GS12 which could not be independently disconnected from the companion Kvant 1 array power feeds.

\section{COMPUTATIONAL ANALYSIS}

A dedicated Fortran computer code was written to assess the MCSA electrical and thermal performance [3]. Computational methodologies were based on those from the NASA Glenn Research Center code SPACE [2] used to predict ISS electrical power system performance. The solar array portion of this code was heavily modified to model the MCSA as installed on the Mir space station. Salient features of the MCSA performance modeling include: Mir orbit mechanics and flight attitude, MCSA sun pointing, transient PPM heat transfer, frontside/backside PPM current-voltage response, degradation, MCSA power harness and power cable resistances and current regulator resistance and diode voltage drop. The code employs nested iteration loops to solve for currents, voltages and temperatures. These features are described in more detail elsewhere [3].
A simplified uncertainty analysis was performed considering all known, presumed independent, sources of analytical uncertainty. Based on modeling methods and input parameters, the root-sum-square (RSS) uncertainty in the computational generator current value is $\pm 6.4 \%$. The RSS uncertainty due to variability in Earth albedo and thermal radiation is $\pm 3.2 \%$. This leads to a total RSS uncertainty in calculated generator current values of $\pm 7.2 \%$.

\section{RESULTS}

\section{MCSA POWER OUTPUT}

Figure 2 shows the orbital variation in MCSA power output in December 1998. Power levels are shown for three locations: (1) the output of the current regulators, (2) the MCSA base and (3) the sum output of all PPMs. The difference in these three power levels represents the power losses in the MCSA harness and in the Mir power cabling and current regulator. Power levels decrease toward the orbit sub-solar point (time $=\sim 65$ minutes) as PPM temperatures increase and the solar cells lose performance.

The average MCSA output power through the orbit sun time is shown in Table 2. Average power levels are also shown for the output of the current regulators, at the MCSA base and as the sum output of all PPMs. Current regulator power is based on data - the product of total MCSA current and the bus voltage, 28.5 volts. The other power levels are based on calculations including system voltage drops. In June 1996, only generators 1, 2, 9-12 were connected. Thus, the lower power levels reflect output from only 38 of the 84 total PPMs.

Over the 2.5 year period from June 1996 to December 1998 , the measured power degradation averages $3.7 \%$ per year. Over the same period, the predicted power degradation was $4.5 \%$ per year. This indicates that overall MCSA electrical performance is excellent, i.e. slightly better than predicted.

\section{CONSISTENCY OF GENERATORS}

As a check of consistency, the output of current generators 1, 8, and 9, each with 6 PPMs, was compared (see Figure 3). For generators with the same illumination and thermal conditions, current output should be the same within $\sim 0.5$ amps. Generators 8 and 9 are consistent with each other and are consistent with predictions (shown as upper and lower bounds of predicted 6-PPM generator performance). Generator 1 current output, however, is $\sim 1$ amp higher than that of companion generators and $\sim 2$ amps higher than that predicted. Figure 4 shows the output of 8-PPM current 
generators (number 2-7). This comparison shows that current outputs are consistent with companion generators and with predictions for all generators except number 6 . The current output of generator 6 is consistently 2 amps lower than companion generators and predictions. Possible reasons for the inconsistent behavior of generators 1 and 6 are discussed in the next section.

\section{COMPARISON OF DATA AND COMPUTATIONS}

The comparison between orbital data and computational values for generator current is shown in Table 3 . The comparison is based on the root-mean-square (RMS) difference in all data points taken throughout the orbit sun period. Considering the combined effect of $5 \%$ data uncertainty and $7 \%$ analysis uncertainty, any comparison within $12 \%$ is favorable. For most generators, the comparison is very favorable, i.e. an RMS difference of $3 \%$ to $8 \%$. For example, the current output of generator 7 versus orbit time is shown in Figure 5 for multiple test dates. The data are well behaved and are consistent with the predicted $8 \%$ current degradation from December 1996 to December 1998.

However, for generator 6 more than 20\% difference in current values existed for the December 1998 test. Figure 6 shows the generator 6 current versus orbit time for multiple test dates. This plot shows a uniform current drop of 2 to 2.5 amps that took place between the December 1996 and December 1998 tests. Since each PPM accounts for 2 to 2.5 amps of the total generator output, these data strongly suggest that one PPM degraded and then failed. MCSA photographs showed micrometeoroid / space debris impact damage to one cell located in the vicinity of generator 6 [5]. This kind of damage would effectively shut down the 10-cell submodule degrading performance. If two submodules are shut down, the PPM does not have sufficient voltage capability to contribute to generator current output.

At the other extreme is generator 1 current values that differed by $15 \%$ and $17 \%$ for the latter two tests. The current versus orbit time plot for this generator, shown in Figure 7 , indicates the measured current levels increased $10-20 \%$ from December 1996 to November 1997. A definitive explanation for this behavior has not been found. Some possibilities considered include: unintended shadowing, unknown short-circuit, current sensor and/or telemetry error, inadvertent connection of a Russian photovoltaic array current generator and dissimilar orbital heating environments (not properly modeled). Another possibility is degraded spacecraft surface albedo. For example, the appearance of brownish contaminant films on Kvant module white radiator surfaces was documented in Mir photo surveys taken in September 1996 and January 1998 [6]. The last possibility considered is a cabling/connection configuration change. This change could have resulted from crew actions following one or both of the following incidents: the Progress collision with Spectre on June 25th, 1997 or the power "brown-out" on November 14th, 1997 during a MCSA power performance test.

Figure 8 shows generator 3 PPM temperatures versus orbit time during the June 1996 test. In this case, calculated temperatures matched measured values during the orbit sun time to within $\sim 5^{\circ} \mathrm{C}$ RMS.

\section{CONCLUSION}

The MCSA has been performing very well since May 1996 when it was deployed. Performance measurement tests were conducted in June 1996, December 1996, November 1997 and December 1998. These data show the MCSA is meeting electrical performance specifications. The data correlated very favorably with computational predictions demonstrating MCSA performance was as expected and amenable to accurate analysis. This favorable comparison further bolsters confidence in the modeling techniques used to forecast ISS solar array performance so important to ISS EPS utilization and mission operations planning. Aside from the probably loss of one PPM, there were no measurable indications of precipitous performance degradation due to contamination or other causes after 2.5 years of operation.

\section{CONTACT}

Thomas $W$. Kerslake is an aerospace engineer in the Power \& Propulsion Office. Phone 216-433-5373. Email kerslake@grc.nasa.gov

\section{REFERENCES}

1. Housten, S., et al., "The Mir Cooperative Solar Array Project," $\underline{47 \text { th }}$ Intersociety Astronautical Congress, paper no. IAA-96-IAA.6.1.106, Beijing, China, 1996.

2. Hojnicki, J. S., et al., "Space Station Freedom Electrical Performance Model," 28th Intersociety Energy Conversion Engineering Conference Proceedings, Atlanta, Georgia, Aug 1993.

3. Kerslake, Thomas W., and Hoffman, David J., "Mir Cooperative Solar Array Flight Performance and Computational Analysis," 32nd Intersociety Energy Conversion Engineering Conference Proceedings, paper no. 97235, Honolulu, Hawaii, Aug 1997.

4. Wilkinson, William, "Mir 1 Cooperative Solar Array Photovoltaic Panel Production," IECEC paper no. AP-265, Aug 1995, p. 353-355.

5. Gaunce, Michael T., et al., "Mir Photo/TV Survey (DTO-1118): STS-79 Mission Report," JSC-27761, March 28, 1997, pp. 20.

6. Gaunce, Michael T. , and Thompson, David R., "Mir Photo/TV Survey (DTO-1118): STS-86 Mission Report," JSC-28194, March 4, 1998 , p. 18-19. 


\begin{tabular}{|l|c|c|c|c|}
\hline \multicolumn{1}{|c|}{ Parameter } & $\begin{array}{c}\text { Jun 20, } \\
1996\end{array}$ & $\begin{array}{c}\text { Dec 19, } \\
1996\end{array}$ & $\begin{array}{c}\text { Nov 20, } \\
1997\end{array}$ & $\begin{array}{c}\text { Dec 01, } \\
1998\end{array}$ \\
\hline Orbit Altitude, km & 394 & 389 & 393 & 358 \\
\hline Orbit Period, min & 92.4 & 92.3 & 92.4 & 91.7 \\
Sun Time, min & 57.5 & 56.4 & 56.6 & 56.2 \\
Eclipse Time, min & 34.9 & 35.9 & 35.8 & 35.5 \\
\hline Solar $\beta$ Angle, ${ }^{\circ}$ & +26.3 & -10.8 & +13.7 & -22.4 \\
\hline Normalized Solar & & & & \\
Insolation & 0.968 & 1.033 & 1.024 & 1.029 \\
\hline Sun Tracking & $3.8 \pm 3$ & $1.6 \pm 3$ & $7.6 \pm 3$ & $4.8 \pm 3$ \\
Error, ${ }^{\circ}$ & & & & \\
\hline
\end{tabular}

Table 1. Mir Flight Attitude and Orbit Parameters

\begin{tabular}{|l|c|c|c|c|}
\hline \multicolumn{1}{|c|}{ Location } & $\begin{array}{c}\text { Jun 20, } \\
1996\end{array}$ & $\begin{array}{c}\text { Dec 19, } \\
1996\end{array}$ & $\begin{array}{c}\text { Nov 20, } \\
1997\end{array}$ & $\begin{array}{c}\text { Dec 01, } \\
1998\end{array}$ \\
\hline Sum of PPMs & 2.84 & 6.31 & 6.15 & 5.92 \\
\hline MCSA Base & 2.45 & 5.42 & 5.29 & 5.12 \\
\hline $\begin{array}{l}\text { Current } \\
\text { Regulator } \\
\text { Output }\end{array}$ & 2.19 & 5.06 & 4.82 & 4.67 \\
\hline $\begin{array}{l}\text { Normalized } \\
\text { Current Regulator } \\
\text { Output* }\end{array}$ & $5.00^{* *}$ & 4.90 & 4.71 & 4.54 \\
\hline
\end{tabular}

* Normalized solar insolation $=1.000$

** - Normalized to 84 active generators

Table 2. MCSA Power Output (kWe)

\begin{tabular}{|c|c|c|c|c|}
\hline Generator Number & $\begin{array}{c}\text { Jun 20, } \\
1996\end{array}$ & $\begin{array}{c}\text { Dec 19, } \\
1996\end{array}$ & $\begin{array}{c}\text { Nov 20, } \\
1997\end{array}$ & $\begin{array}{c}\text { Dec 01, } \\
1998\end{array}$ \\
\hline 1 & 6.8 & 4.3 & $15.2^{*}$ & $16.8^{*}$ \\
\hline 2 & 3.4 & 3.0 & 4.1 & 4.9 \\
\hline 3 & nd & 5.2 & 7.5 & 8.7 \\
\hline 4 & nd & 2.0 & 4.4 & 5.1 \\
\hline 5 & nd & 6.1 & 8.4 & 8.9 \\
\hline 6 & nd & 5.5 & 8.5 & $21.4^{* *}$ \\
\hline 7 & nd & 3.3 & 4.0 & 3.4 \\
\hline 8 & nd & 6.2 & 6.2 & 7.0 \\
\hline 9 & 7.3 & 8.9 & 3.4 & 4.9 \\
\hline 10 & 4.5 & nd & nd & nd \\
\hline Average & 5.5 & 4.9 & 6.8 & 9.0 \\
\hline
\end{tabular}

nd - no data "-Generator power increase "*-Probable loss of a PPM

Table 3. RMS Difference (\%) Between Measured $\&$ Calculated Generator Currents ( $\mathrm{nd}=$ no data)

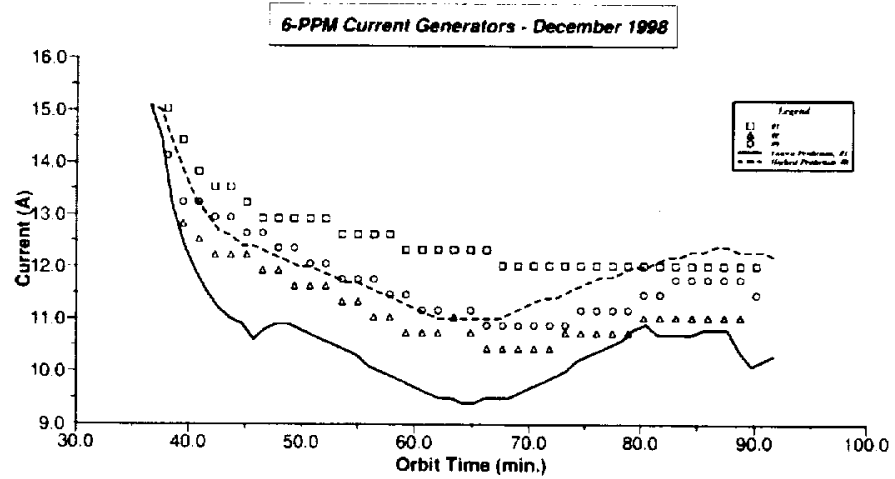

Figure 3. Output of Current Generators with 6 PPMs 


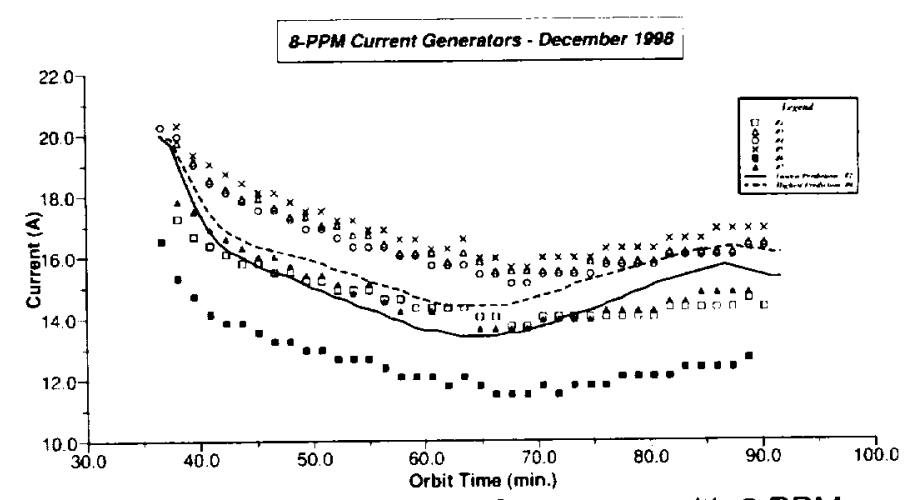

Figure 4. Output of Current Generators with 8 PPMs

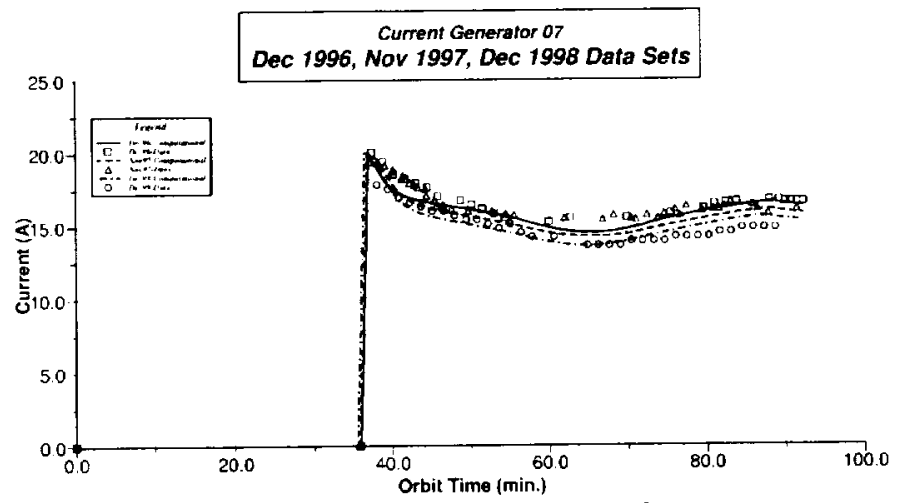

Figure 5. Generator 7 Current Output

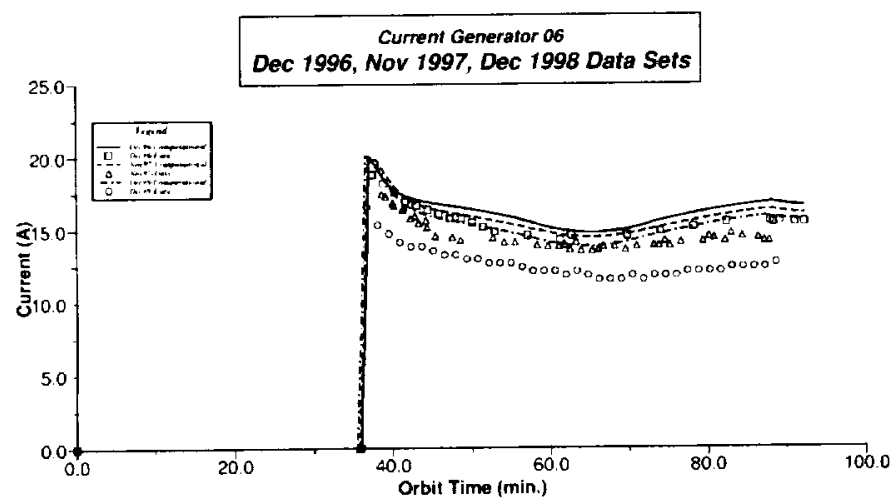

Figure 6. Generator 6 Current Output

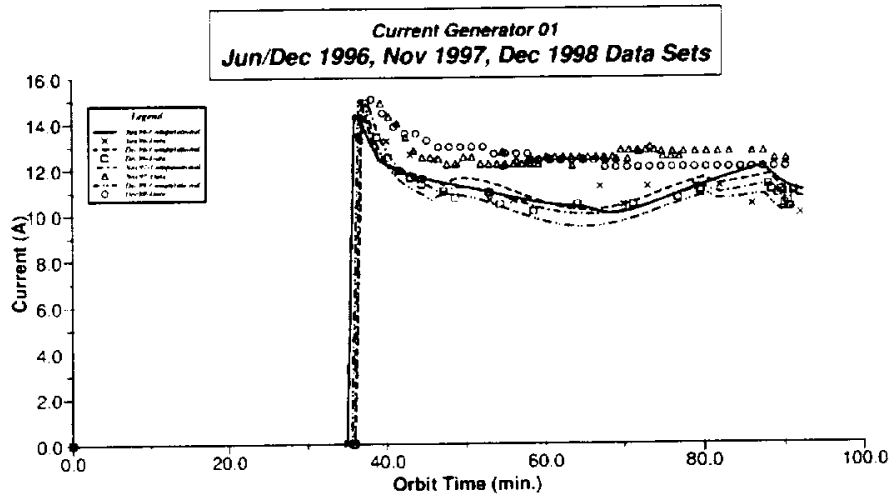

Figure 7. Generator 1 Current Output

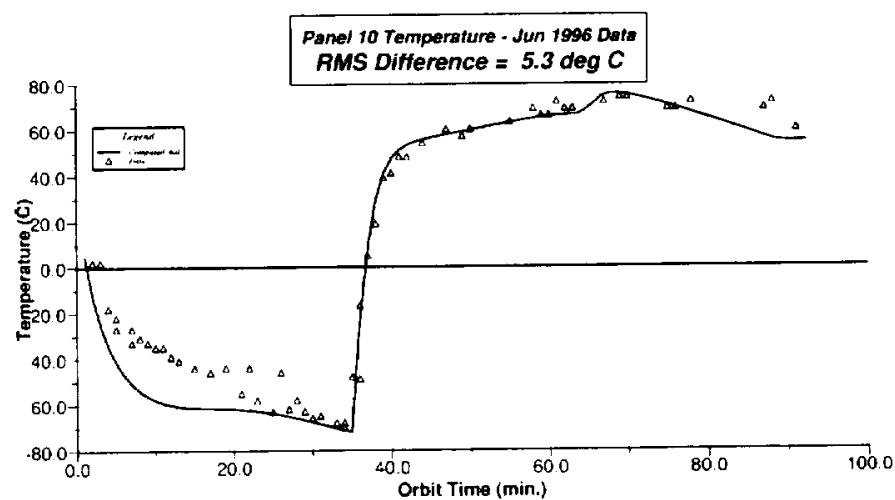

Figure 8. Generator 3 PPM Temperature in June 1996 
Public reporting burden for this collection of information is estimated to average 1 hour per response. including the time for reviewing instructions, searching existing data sources, gathering and maintaining the data needed, and completing and reviewing the collection of information. Send comments regarding this burden estimate or any other aspect of this ( Davis Highway. Suite 1204. Artington, VA 22202-4302, and to the Office of Management and Budget, Paperwork Reduction Project (0704-0188). Washington. DC 20503.

\begin{tabular}{|l|r|r|}
\hline 1. AGENCY USE ONLY (Leave blank) & $\begin{array}{r}\text { 2. REPORT DATE } \\
\text { July } 1999\end{array}$ & $\begin{array}{r}\text { 3. REPORT TYPE AND DATES COVERED } \\
\text { Technical Memorandum }\end{array}$ \\
\hline
\end{tabular}

\section{TITLE AND SUBTITLE}

Performance of the Mir Cooperative Solar Array After 2.5 Years in Orbit
5. FUNDING NUMBERS

$$
\text { WU }-478-12-10-00
$$

8. Performing organization REPORT NUMBER

$E-11757$

10. SPONSORING/MONITORING AGENCY REPORT NUMBER

NASA TM-1999-209287

SAE $99-(01-26.32$

\section{SUPPLEMENTARY NOTES}

Prepared for the 34th Intersociety Energy Conversion Engineering Conference sponsored by the Society of Automotive Engineers, Vancouver. British Columbia. Canada, August 1-5. 1999. Responsible person, Thomas W. Kerslake. organization code 6920, (216) 433-5373.

12a. DISTRIBUTION/AVAILABILITY STATEMENT

12b. DISTRIBUTION CODE

Unclassified - Unlimited

Subject Categories: 18 and 20

Distribution: Nonstandard

This publication is ilvailable from the NASA Center for AeroSpace Information. (301) 621-0390.

13. ABSTRACT (Maximum 200 words)

The Mir Cooperative Solar Array (MCSA) was developed jointly by the United States and Russia to produce $6 \mathrm{~kW}$ of power for the Russian space station Mir: Four, multiorbit test sequences were executed between June 1996 and December 1998 to measure MCSA electrical performance. A dedicated Fortran computer code was developed to analyze the detailed thermal-electrical performance of the MCSA. The computational performance results compared very favorably with the measured flight data in most cases. Minor performance degradation was detected in one current generating section of the MCSA. Yet overall, the flight data indicated the MCSA was meeting and exceeding performance expectations. There was no precipitous performance loss due to contamination or other causes after 2.5 years of operation. In this paper, we review the MCSA flight electrical performance tests, data and computational modeling and discuss findings from data comparisons with the computational results.

14. SUBJECT TERMS

Solar arrays: Mir Space Station: Electric power: Performance tests; Orbital space tests; Flight tests

\begin{tabular}{|c|c|c|}
\hline $\begin{array}{c}\text { 17. SECURITY CLASSIFICATION } \\
\text { OF REPORT } \\
\text { Unclassified }\end{array}$ & $\begin{array}{c}\text { 18. SECUAITY CLASSIFICATION } \\
\text { OF THIS PAGE } \\
\text { Unclassified }\end{array}$ & $\begin{array}{c}\text { 19. SECURITY CLASSIFICATION } \\
\text { OF ABSTRACT } \\
\text { Unclassified }\end{array}$ \\
\hline
\end{tabular}

